\title{
Profile of Endometrial Cancer Patients in the Third Referral Hospital in Surabaya based on Known Risk Factors
}

\author{
Nihal Sofyan ${ }^{1}$, I Ketut Sudiana², Brahmana Askandar ${ }^{3 *}$ \\ ${ }^{1}$ Faculty of Medicine, Universitas Airlangga, Surabaya, Indonesia \\ ${ }^{2}$ Department of Patology Anatomy, Faculty of Medicine, Universitas Airlangga - Dr.Soetomo General Hospital, Surabaya, \\ Indonesia \\ ${ }^{3}$ Department of Obstetrics and Gynecology, Faculty of Medicine, Universitas Airlangga - Dr. Soetomo General Hospital, \\ Surabaya, Indonesia
}

\section{A R T I C L E I N F O}

\section{Article history:}

Received 21 September 2020

Received in revised form 27

October 2020

Accepted 29 October 2020

Available online 31 October 2020

\section{Keywords:}

Endometrial cancer,

Risk factor,

Descriptive study.

*) Corresponding author:

brahmanaaskandar@yahoo.com

\begin{abstract}
A B S T R A C T
Introduction: Endometrial cancer is a malignant tumor of primary endometrial epithelium that placed as the sixth most common cancer in women worldwide. The exact cause of it is still unknown although there are several risk factors has been well studied and the incidence rate is increasing every year. The aim of the study is to describe the profile of endometrial cancer patients in third referral hospital in Surabaya based on known risk factors.

Methods: We collected data retrospectively through the medical record of outpatients with endometrial cancer diagnosis from January-December 2016. A total of 120 patients were collected and only 95 patients who meet the inclusion criteria. Data about age, age of menarche, status of menopause, parity, Body Mass Index (BMI), history of disease, and family history of cancer were extracted then presented descriptively.

Results: From 95 patients, the largest distribution were age 51-60 years old (47,37\%), and was diagnosed mostly in women with parity $\leq 2(47,37 \%)$, postmenopausal status $(61,05 \%)$, age of menarche $\geq 12(85,26 \%)$, and normal weight $(35,79 \%)$. Most of patients didn't have either any history of disease $(57,89 \%)$ or family history of cancer $(89,47 \%)$.

Conclusion: Most of the endometrial cancer patients in Dr. Soetomo General hospital Surabaya were women aged 51-60 years old with postmenopausal status, age of menarche $\geq 12$ years old, number of parities $\leq 2$, and normal weight. The majority of them were also found to have no history of disease and family history of cancer.
\end{abstract}

\section{Introduction}

Endometrial cancer is the sixth most common cancer in worldwide for women (rank fifteenth for overall cancer), with 320,000 new cases were diagnosed in 2012 and the proportion was nearly 5\% of all new cases of cancer in women $(2 \%$ of overall cancer that occurs in the world). ${ }^{1}$ In the United States, endometrial cancer is ranked fourth in the most diagnosed female gynecological cancer. ${ }^{2}$ The incidence of this disease is relatively high in developed countries such as North America and Europe while in developing countries such as Southeast Asia and Africa the incidence of endometrial cancer is relatively lower. ${ }^{1}$

Cancer in Indonesia is ranked fifth as the cause of death due to the increasing number of cancer patients through years along with the increasing life expectancy of Indonesian women. More than $40 \%$ of female malignancies are gynecological cancers. Endometrial cancer is still not widely known by the public in
Indonesia and the types of cancer that are usually known among women are breast cancer, cervical cancer, or uterine cancer. In terms of descriptive epidemiological aspects, there are still no clear data on the number of endometrial cancer cases in Indonesia, especially in international publication. ${ }^{3}$

In 2016, the distribution of new endometrial cancer patient's visit in Dr. Soetomo General Hospital Surabaya was 122 patients, about $9.4 \%$ of the total cancer patients. This number increased compared to 2015 , where the distribution was only 99 new patients ( $9 \%$ of total cancer patients) and in 2014 as many as 36 patients ( $4 \%$ of total cancer patients). ${ }^{4}$ Although the mortality rate of endometrial cancer is smaller than other cancers, it does not mean endometrial cancer is not dangerous. This cancer is really need serious concern if there is symptom of abnormal uterine bleeding especially in postmenopausal women. The survival rate of endometrial cancer depends on the age of the patient, 
stage at diagnosis, and apparently certain type of cells that seem worse in developing countries. ${ }^{2}$

Endometrial cancer has several risk factors that might be known by the public due to the increasing of its incidence every year. One of the endometrial risk factors is obesity which can increase estrogen levels in a woman's body. In addition, postmenopausal use of estrogen that was not accompanied by progestin, late menopause, nulliparity, and a history of polycystic ovary syndrome can also increase the risk of it. Other medical conditions that can increase the risk are lynch syndrome, diabetes, and hypertension. Whereas pregnancy, use of oral contraceptives or intrauterine devices, and physical activity can reduce the risk of endometrial cancer. $^{2}$ The risk of endometrial cancer is increasing with age and most of it are diagnosed at postmenopausal state. The median age when diagnosed is 61 years. ${ }^{5}$ Unlike breast cancer and cervical cancer where the screening tests are publicly available, there is no standard for screening tests for women at risk of endometrial cancer. However, most of endometrial cancer cases can be diagnosed at early stage in symptomatic patients, such as after report of vaginal bleeding in postmenopausal patients. ${ }^{2,6}$

Treatment that can be done for endometrial cancer patients are surgery, radiotherapy, hormone therapy, and chemotherapy which depends on the stage of it. Women should be given more education about risk factors and symptoms of endometrial cancer earlier and immediately report unexpected uterine bleeding to the doctor. ${ }^{3}$

Profile of endometrial cancer patients at Dr. Soetomo General Hospital Surabaya in terms of several known risk factors had not been well studied and analyzed yet. Therefore, research needs to be done as strategy for prevention and provide information about several risk factors that can affect the incidence of endometrial cancer in the future.

\section{Methods}

This research was a descriptive study with cross sectional approach. The population was outpatient's medical record data with endometrial cancer diagnosis in Obstetrics and Gynecology Outpatient at Dr. Soetomo General Hospital Surabaya from January - December 2016. Samples were obtained based on the who meet the inclusion criteria. The inclusion criteria was patient who had complete data according to variables. Data about Age, age of menarche, status of menopause, parity, Body Mass Index (BMI), history of disease, and family history of cancer were extracted, while incomplete medical records were excluded. The number of collected patients were 120 patients, but only 95 patients who meet the inclusion criteria. Then all data processed using Microsoft Excel and presented descriptively. This study has been approved by Health Research and Ethics Committee Dr. Soetomo General Hospital Surabaya (0143 / KEPK / IV / 2018).

\section{Results}

Of total 95 subjects, the majority of age was 51-60 years old $(45.37 \%)$ while the majority of age of menarche is $\geq$ 12 years old $(85.26 \%) .56$ patients $(61.05 \%)$ were found already in postmenopausal status and the majority of parity were patients who had number of parity $\leq 2(57.89 \%)$. Besides, as many as 34 patients $(35,79 \%)$ is in normal weight.
Table 1. The characteristics of patients in terms of several risk factors

\begin{tabular}{ll}
\hline \multicolumn{1}{c}{ Variable } & $\mathrm{n}=95(\%)$ \\
\hline Age & $10(10.53 \%)$ \\
\hline$<40$ years old & $20(21.05 \%)$ \\
\hline $40-50$ years old & $45(47.37 \%)$ \\
\hline $51-60$ years old & $20(21.05 \%)$ \\
\hline$>60$ years old & $14(14.74 \%)$ \\
\hline Age of Menarche & $81(85.26 \%)$ \\
\hline$<12$ years old & $7(36.8 \%)$ \\
\hline$\geq 12$ years old & $37(38.95 \%)$ \\
\hline Status of Menopause & $58(61.05 \%)$ \\
\hline Premenopausal $(24-58$ years old $)$ & \\
\hline Postmenopausal $(46-71$ years old $)$ & $55(57.89 \%)$ \\
\hline Number of Parity & $40(42.11 \%)$ \\
\hline$\leq 2$ & \\
\hline$>2$ & $11(11,58 \%)$ \\
\hline BMI & $34(35,79 \%)$ \\
\hline Underweight $(<18,5 \mathrm{~kg} / \mathrm{m} 2)$ & $29(30,53 \%)$ \\
\hline Normal weight $(18,5-24,9 \mathrm{~kg} / \mathrm{m} 2)$ & $21(22,11 \%)$ \\
\hline Overweight $(25-29,9 \mathrm{~kg} / \mathrm{m} 2)$ &
\end{tabular}

Results revealed that most of patients $(55.89 \%)$ had no history of disease, then second largest distribution is hypertension $(27.37 \%)$ then followed by diabetes $(17.89 \%)$. Tumors and asthma were obtained respectively 3 patients $(3.16 \%)$, then cardiovascular disease and gout were only $2.11 \%$. Whereas the least distribution of patient history of disease is cancer $(1.05 \%)$. Among patients with history of tumor, one of them had breast tumor and the other had myoma. The only patient with history of cancer was diagnosed as breast cancer. Lastly, most of patients did not have any family history of cancer $(89,47 \%)$.

Table 2. Surgery classification

\begin{tabular}{ll}
\hline \multicolumn{1}{c}{ Variable } & \multicolumn{1}{c}{$\mathrm{n}(\%)$} \\
\hline History of Disease & $17(17.89 \%)$ \\
\hline Diabetes & $26(27.37 \%)$ \\
\hline Hypertension & $2(2.11 \%)$ \\
\hline Cardiovascular disease & $1(1.05 \%)$ \\
\hline Cancer & $3(3.16 \%)$ \\
\hline Tumor & $3(3.16 \%)$ \\
\hline Asthma & $2(2.11 \%)$ \\
\hline Gout & $55(57.89 \%)$ \\
\hline No history of disease & \\
\hline Family history of cancer & $10(10,53 \%)$ \\
\hline Cancer & $85(89,47 \%)$ \\
\hline No family history of cancer
\end{tabular}




\section{Discussion}

Age is one of the factors that can increase the risk of endometrial cancer and the majority of women were diagnosed in peri or postmenopausal between the age of 50 and 65.6 years old with the average age at diagnosis is 61.2 years old. ${ }^{2}$ This result is similar with another study in Dr. Sardjito Public Hospital, stating that the distribution of endometrial cancer patients with age $>50$ years old is higher than patients age $\leq 50$ years old. ${ }^{7}$ Thus, endometrial cancer most commonly attacked postmenopausal women between $50-65$ years old. ${ }^{8}$

The majority of age of menarche in this study is $\geq$ 12 years old. This result is different with the research conducted by $\mathrm{Xu}$ et al. (2003) stating that women with age of menarche $\geq 17$ years old had a $45 \%$ lower risk of endometrial cancer than women with age of menarche $\leq 12$ years old. ${ }^{9}$ There are several factors that can significantly affect the age of menarche, namely genetics, environmental conditions, body stature, family body size, body mass index, socioeconomic status, and education level. ${ }^{10}$ In Indonesia average age of menarche based on Baseline Health Research's data is similar with this study which is $\geq 12$ years old group. ${ }^{11}$ So, the discrepancy between the results of this study with some previous is likely due to the absence of menopausal age data while in the previous studies have recorded patients menstrual ranges from menarche to menopause time. This could explain that the total time at which a woman is exposed to estrogen (menstruation span) is important and the effect is limited by time. ${ }^{12}$

$\mathrm{Xu}$ et al. (2003) stated that $75 \%$ of endometrial cancers occur during the postmenopausal period. ${ }^{9}$ The number of menstrual years including menopausal status illustrates the cumulative exposure of women to endogenous estrogen which is an important predictor and independent risk of endometrial cancer. ${ }^{13}$ The increasing lifetime exposure to estrogen through early menarche or late menopause could be associated with the risk of endometrial cancer, that is because of estrogen mechanism in inducing endometrial proliferation through local production of insulin-like growth factor-1 (IGF-1). Furthermore, it increases the risk of accumulating genetic mutations in proto-oncogenes and tumor suppressor genes..$^{13,14}$

We found most endometrial cancer patients had the number of parity $\leq 2(57.89 \%)$. This is analogous with the research conducted by $\mathrm{Wu}$ et al. (2003), stating that women who have given birth to a child are associated with a reduced risk in endometrial cancer. ${ }^{15}$ Other literature also states that there is a reduced risk of death in all age groups based on the number of children. The reduction in mortality was $9.2 \%$ for each addition of one child. ${ }^{16}$ The role of parity in reducing the risk of endometrial cancer can be going through two mechanisms. Firstly, the low concentration of estrogen and the high concentration of progesterone during pregnancy can be linked as a protective effect by the function of progesterone hormone as an inhibitor of cell proliferation and stimulator of cell differentiation in the endometrium. Secondly, premalignant or malignant cells could shed off during the birth process or the third stage of labour. ${ }^{17}$ Breastfeeding can also reduce the risk of endometrial cancer especially if done in the long term, although the mechanism is still debated. ${ }^{18}$ Therefore, women with more births may also have a long history of breastfeeding so it can be a protective effect on the risk of endometrial cancer.

In women, an increase in BMI is more related to the risk of endometrial cancer than any other types of cancer and BMI is the most common measurement in clinical diagnosis of obesity. ${ }^{14,19}$ In this study, the largest distribution of BMI was the normal weight group. This result is similar with the research in Dr. Sardjito Hospital that 61.8\% endometrial cancer patients were in normal weight. ${ }^{7}$ While other study stated that the increased in BMI was associated with increased in malignancy of endometrial cancer.20 The association of increased BMI with the incidence of endometrial cancer is probably related to adipose tissue as the main source of the hormone estrogen in postmenopausal women and the drastic increase in estrogen in overweight or obese individuals will cause hyperplastic growth in the endometrium. ${ }^{14,21}$ The discrepancy between the results obtained in this study and the others may be due to several reasons. First, the prevalence of obesity in adult women is different in each country, where as the prevalence of obesity in Indonesia is lower compared to United states. ${ }^{22}$, ${ }^{23}$ Furthermore, BMI gradually increases during adulthood and reaches a peak at the age of 50-59 years, after the age of 60 years body weight and BMI tend to decrease. ${ }^{24}$ Apart from BMI, the best predictor of risk in cancer is using body fat. ${ }^{14}$ Another possibility is that the measurement of BMI in some patients is carried out in late stage endometrial cancer because weight loss after diagnosis and treatment of endometrial cancer can be an adverse prognostic factor. ${ }^{25}$ History of disease that were obtained in this study were highest in those who did not have a history of disease. This is similar with study in Italy and Switzerland stating that the distribution of patients who had no history of diabetes and hypertension are higher than those who had a history of the disease. This might be happened because of the association between endometrial cancer with diabetes and hypertension can be modified with BMI and physical activity, while in this study most of the patients is in normal BMI. ${ }^{26}$ While among the disease, hypertension is a disease that has the most common distribution in this study. The increased risk of endometrial cancer was associated with an increase in diastolic and systolic blood pressure. ${ }^{27}$ The biological mechanism that links them is still unclear but can also be associated with insulin resistance. ${ }^{28}$ The second most common disease in this study is diabetes. This result is in accordance with previous prospective studies that reported an increased risk of endometrial cancer is related to diabetes. ${ }^{29}$ The mechanism of diabetes in increasing the risk of endometrial cancer could be related with Insulin resistance and hyperinsulinemia. ${ }^{30,31}$ Hyperinsulinemia affects carcinogenesis which indirectly stimulates the growth of endometrial stromal cells by inhibiting the production of Insulin-like Growth Factor Binding Protein-1 and increasing bioactive levels of IGF-1. IGF-1 has antiapoptotic activity and can increase cell proliferation then stimulating neoplastic cell growth. ${ }^{32}$

Most of study found that family genetic factors play a big role in the risk of endometrial cancer. ${ }^{33,34}$ However, Karageorgi et al. (2009) obtained research from 95,638 endometrial cancer patients, but only $3 \%$ had a family 
history of endometrial cancer. ${ }^{35}$ A genetic disorder mechanism that plays an important role in the development of endometrial cancer in young women is hereditary nonpolyposis colorectal cancer (HNPCC) and the average age for developing endometrial cancer due to a mutase in one of the HNPCC genes is under 50 years and carriers of the mutation have $50 \%$ lifetime risk of endometrial cancer. The possibility that makes the results of this study different from previous studies is another risk factor that also influences the family history of cancer, namely BMI. ${ }^{35}$ Broadly speaking, there are two causes of genetic damage in cancer, namely external and internal factors. Therefore, as the cause of endometrial cancer is unknown in certain, so apart from genetic factors, there are another risk factor that likely play greater role (namely; reproductive factors, menstruation, hormones, oral contraceptives, and etc). ${ }^{36}$

\section{Conclusion}

Most of the endometrial cancer patients in Dr. Soetomo General hospital Surabaya were women aged 51-60 years old with postmenopausal status, age of menarche $\geq 12$ years old, number of parity $\leq 2$, and normal weight. The majority of them also were found to have no history of disease and family history of cancer. Further research about risk factor of endometrial cancer with more variables and other method is needed for more accurate results.

\section{Conflict of Interest}

The author stated there is no conflict of interest

\section{References}

1. Nichols RL. Preventing Surgical Site Infections : A Surgeon's 1. Ferlay J, Soerjomataram I, Dikshit R, et al. Cancer Incidence and Mortality Worldwide: Sources, Methods and Major Patterns in GLOBOCAN 2012. International Journal of Cancer. 2015; 136: E359-86

2. Society AC. Cancer Facts \& Figures 2017. Georgia: American Cancer Society, 2017.

3. Aziz MF. Gynecological Cancer in Indonesia. Journal of Gynecologic Oncology. 2009; 20: 8-10.

4. Laporan Kunjungan Poli, Tindakan \& Jadwal Operasi OnkologiGinekologi 2015-2016. Surabaya: Fakultas Kedokteran Universitas Airlangga - RSUD Dr. Soetomo, 2017.

5. Howlader N, Noone A, Krapcho M, et al. SEER Cancer Statistics Review, 1975-2008. Maryland: National Cancer Institute, 2011.

6. Leslie KK, Thiel KW, Goodheart MJ, De Geest K, Jia Y and Yang S. Endometrial Cancer. Obstetrics and Gynecology Clinics of North America. 2012; 39: 255-68.

7. Pradjatmo H and Pahlevi DP. Status Gizi sebagai Faktor Prognosis Penderita Karsinoma Endometrium. Jurnal Gizi Klinik Indonesia. 2013; 10: $10-8$

8. Gibbs RS and Danforth DN. Danforth's Obstetrics and Gynecology. Lippincott Williams \& Wilkins, 2008.

9. Xu WH, Xiang YB, Ruan ZX, et al. Menstrual and Reproductive Factors and Endometrial Cancer Risk: Results from a Population-Based CaseControl Study in Urban Shanghai. International Journal of Cancer. 2004; 108: 613-9.

10. Ameade EP and Garti HA. Age at Menarche and Factors that Influence It: A Study among Female University Students in Tamale, Northern Ghana. PloS one. 2016; 11: $\mathrm{e} 0155310$

11. Indonesia KKR. Riset Kesehatan Dasar 2010. Jakarta: Kementerian Kesehatan Republik Indonesia, 2010.

12. Pettersson B, Adami H-O, Bergström R and Johansson EDB. Menstruation Span - a Time-Limited Risk Factor for Endometrial Carcinoma. Acta obstetricia et gynecologica Scandinavica. 1986; 65: 247-55.

13. Gavrilyuk O, Braaten T, Weiderpass E, Licaj I and Lund E. Lifetime Number of Years of Menstruation as a Risk Index for Postmenopausal Endometrial Cancer in the Norwegian Women and Cancer Study. Acta obstetricia et gynecologica Scandinavica. 2018; 97: 1168-77.
14. Kitson SJ, Evans DG and Crosbie EJ. Identifying High-Risk Women for Endometrial Cancer Prevention Strategies: Proposal of an Endometrial Cancer Risk Prediction Model. Cancer prevention research (Philadelphia, Pa). 2017; 10: 1-13.

15. Wu QJ, Li YY, Tu C, et al. Parity and Endometrial Cancer Risk: A MetaAnalysis of Epidemiological Studies. Scientific Reports. 2015; 5: 14243

16. Løchen M-L and Lund E. Childbearing and Mortality from Cancer of the Corpus Uteri. Acta obstetricia et gynecologica Scandinavica. 1997; 76: 373-7.

17. Abacjew-Chmyłk AO, Chmyłko Ł, Wydra DG, Olszewska H, Kobiela $\mathrm{P}$ and Ciach K. Multiple Multiparity is a Negative Prognostic Factor for Endometrial Cancer in Poland. Ginekologia polska. 2016; 87: 178-82.

18. Jordan SJ, Na R, Johnatty SE, et al. Breastfeeding and Endometrial Cancer Risk: An Analysis From the Epidemiology of Endometrial Cancer Consortium. Obstetrics and gynecology. 2017; 129: 1059-67.

19. Reeves GK, Pirie K, Beral V, Green J, Spencer E and Bull D. Cancer Incidence and Mortality in Relation to Body Mass Index in the Million Women Study: cohort study. Bmj. 2007; 335: 1134.

20. Renehan AG, Tyson M, Egger M, Heller RF and Zwahlen M. Body-Mass Index and Incidence of Cancer: A Systematic Review and Meta-Analysis of Prospective Observational Studies. Lancet (London, England). 2008; 371: 569-78.

21. Schmandt RE, Iglesias DA, Co NN and Lu KH. Understanding Obesity and Endometrial Cancer Risk: Opportunities for Prevention. American Journal of Obstetrics and Gynecology. 2011; 205: 518-25.

22. Indonesia KKR. Laporan Riset Kesehatan Dasar Tahun 2013. Jakarta: Kementerian Kesehatan Republik Indonesia, 2013.

23. Hales CM, Carroll MD, Fryar CD and Ogden CL. Prevalence of Obesity among Adults and Youth: United States, 2015-2016. NCHS Data Brief. 2017: 1-8.

24. Villareal DT, Apovian CM, Kushner RF and Klein S. Obesity in Older Adults: Technical Review and Position Statement of the American Society for Nutrition and NAASO, The Obesity Society. The American Journal of Clinical Nutrition. 2005; 82: 923-34.

25. El-Safadi S, Sauerbier A, Hackethal A and Münstedt K. Body Weight Changes after the Diagnosis of Endometrial Cancer and Their Influences on Disease-Related Prognosis. Archives of Gynecology and Obstetrics. 2012; 285: 1725-9.

26. Lucenteforte E, Bosetti C, Talamini R, et al. Diabetes and Endometrial Cancer: Effect Modification by Body Weight, Physical Activity and Hypertension. British Journal of Cancer. 2007; 97: 995-8.

27. Bjørge T, Stocks T, Lukanova A, et al. Metabolic Syndrome and Endometrial Carcinoma. American Journal of Epidemiology. 2010; 171: 892-902.

28. Tooke JE and Hannemann MM. Adverse Endothelial Function and the Insulin Resistance Syndrome. Journal of Internal Medicine. 2000; 247: 425-31.

29. Ju W, Kim HJ, Hankinson SE, De Vivo I and Cho E. Prospective Study of Body Fat Distribution and the Risk of Endometrial Cancer. Cancer Epidemiology. 2015; 39: 567-70.

30. Gunter MJ, Hoover DR, Yu H, et al. A Prospective Evaluation of Insulin and Insulin-Like Growth Factor-I as Risk Factors for Endometrial Cancer. Cancer Epidemiology, Biomarkers \& Prevention : A Publication of the American Association for Cancer Research, cosponsored by the American Society of Preventive Oncology. 2008; 17: 921-9.

31. Mu N, Zhu Y, Wang Y, Zhang H and Xue F. Insulin Resistance: A Significant Risk Factor of Endometrial Cancer. Gynecologic Oncology. 2012; 125: 751-7.

32. Joung KH, Jeong JW and Ku BJ. The Association between Type 2 Diabetes Mellitus and Women Cancer: The Epidemiological Evidences and Putative Mechanisms. BioMed Research International. 2015; 2015: 920618.

33. Win AK, Reece JC and Ryan S. Family History and Risk of Endometrial Cancer: A Systematic Review and Meta-Analysis. Obstetrics and Gynecology. 2015; 125: 89-98.

34. Dossus L, Allen N, Kaaks R, et al. Reproductive Risk Factors and Endometrial Cancer: The European Prospective Investigation into Cancer and Nutrition. International Journal of Cancer. 2010; 127: 442-51.

35. Karageorgi S, Hankinson SE, Kraft P and De Vivo I. Reproductive Factors and Postmenopausal Hormone Use in Relation to Endometrial Cancer Risk in the Nurses' Health Study Cohort 1976-2004. International Journal of Cancer. 2010; 126: 208-16.

36. Berends MJW, Kleibeuker JH, de Vries EGE, et al. The Importance of Family History in Young Patients with Endometrial Cancer. European Journal of Obstetrics \& Gynecology and Reproductive Biology. 1999; 82: 139-41. 